\title{
Analysis of CT Scans Findings in Seizures Patients: An Observational Study
}

\author{
Niranjan Bapu saheb Patil ${ }^{1}$, Nitin Dashrath Wadhwani² \\ ${ }^{1}$ Professor, Department of Radiodiagnosis,D.Y.Patil Medical College, Kolhapur, ${ }^{2}$ Professor \& HOD, Department of Radiodiagnosis, D.Y.Patil Medical College, \\ Kolhapur.
}

\section{Abstract}

Background: Seizures may occur in up to $10 \%$ of the population. There is general consensus that adults with an unprovoked first seizure should have brain imaging with either CT or MRI primarily to identify any process that may be responsible for the seizure. Hence; under the light of above mentioned data, the present study was planned for assessing CT scans and their findings in seizures patients. Subjects and Methods: All the patients reporting with the history of seizure disorder were admitted to the emergency department and were treated accordingly. Complete past medical and clinical history of all the patients was obtained. In all the patients, EEG was done and findings of the EEG were correlated with the final diagnosis. In all the patients CT scan was done. Diagnosis was confirmed after correlating the clinical findings of all the patients with clinical history and microbiological investigation reports. All the results were analyzed by SPSS software .Results: Tuberculoma was found to be present among in 18 patients with partial seizures. Cerebral infarct was found to be present in 10 patients with partial seizures and among 15 patients with generalized seizures. Focal cerebral edema was found to be present in 10 patients with partial seizures. Diffuse cerebral edema was found to be present in 13 patients with generalized seizures. Brain tumour was found to be present among 6 patients with partial seizures. Calcifications were found to be present in 4 patients with partial seizures and 10 patients with generalized seizures. Conclusion: CT is sensitive for detection of neural lesions and is advocated in seizure patients. However; further studies are recommended.

Keywords: Computed tomography, Seizures.

Corresponding Author: Dr. Nitin Dashrath Wadhwani, Professor \& HOD, Department of Radiodiagnosis, D.Y.Patil Medical College, Kolhapur.

Received: June 2019

Accepted: June 2019

\section{Introduction}

Seizures may occur in up to $10 \%$ of the population, whereas epilepsy is a chronic disease that is characterized by recurrent seizures that may affect about $2 \%$ of the population. Although primarily defined by EEG abnormalities, it is presently recognized that epilepsy is often associated with gross or subtle structural or metabolic lesions of the brain. ${ }^{[1-3]}$ There is general consensus that adults with an unprovoked first seizure should have brain imaging with either CT or MRI primarily to identify any process that may be responsible for the seizure. However, limited information is available on imaging findings in these patients. CT is generally readily available and excludes problems that require immediate attention in an acute setting.4- 6 Hence; under the light of above mentioned data, the present study was planned for assessing CT scans and their findings in seizures patients.

\section{Subjects and Methods}

The present study was conducted in the department of radio-diagnosis of the medical institute and it included assessment of analysis of CT scans findings in seizures patients. Ethical approval was obtained from institutional ethical committee and written consent was obtained after explaining in detail the entire research protocol. All the patients reporting with the history of seizure disorder were admitted to the emergency department and were treated accordingly. Complete past medical and clinical history of all the patients was obtained. In all the patients, EEG was done and findings of the EEG were correlated with the final diagnosis. In all the patients CT scan was done. Diagnosis was confirmed after correlating the clinical findings of all the patients with clinical history and microbiological investigation reports. All the results were analysed by SPSS software. Chi-square test and student t test were used for the assessment of level of significance.

\section{Results}

In the present study, a total of 200 seizer patients were enrolled. Among these patients, 100 patients were with partial seizure while the remaining 100 patients were of generalized seizure. Among these 200 patients, 115 were 


\section{Pattil \& Wadhwani; Analysis of CF Scans Findings in Seizures Patients}

males while the remaining 85 were females. 54 patients belonged to the age group of less than 20 years, whereas 50 patients belonged to the age group of 20 to 40 years. Remaining 46 patients belonged to the age group of 40 to 60 years. Tuberculoma was found to be present among in 18 patients with partial seizures. Cerebral infarct was found to be present in 10 patients with partial seizures and among 15 patients with generalized seizures. Focal cerebral edema was found to be present in 10 patients with partial seizures. Diffuse cerebral edema was found to be present in 13 patients with generalized seizures. Brain tumour was found to be present among 6 patients with partial seizures. Calcifications were found to be present in 4 patients with partial seizures and 10 patients with generalized seizures.

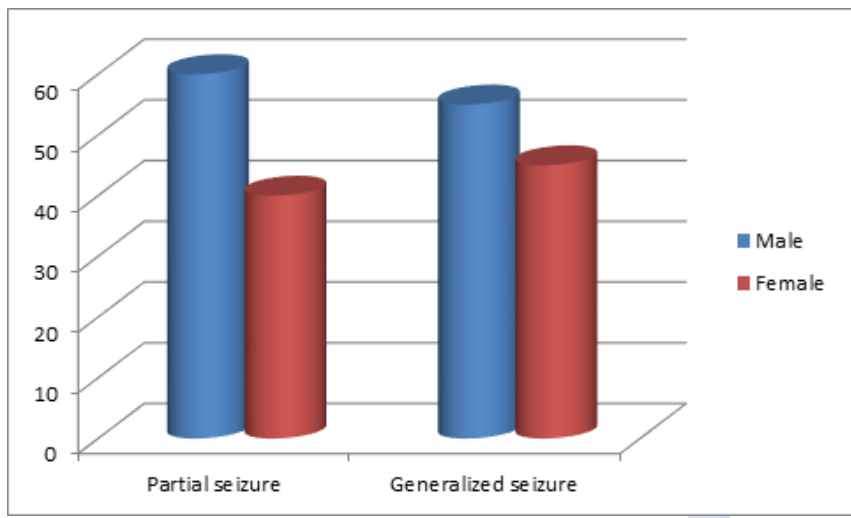

Figure 1: Demographic details of patients

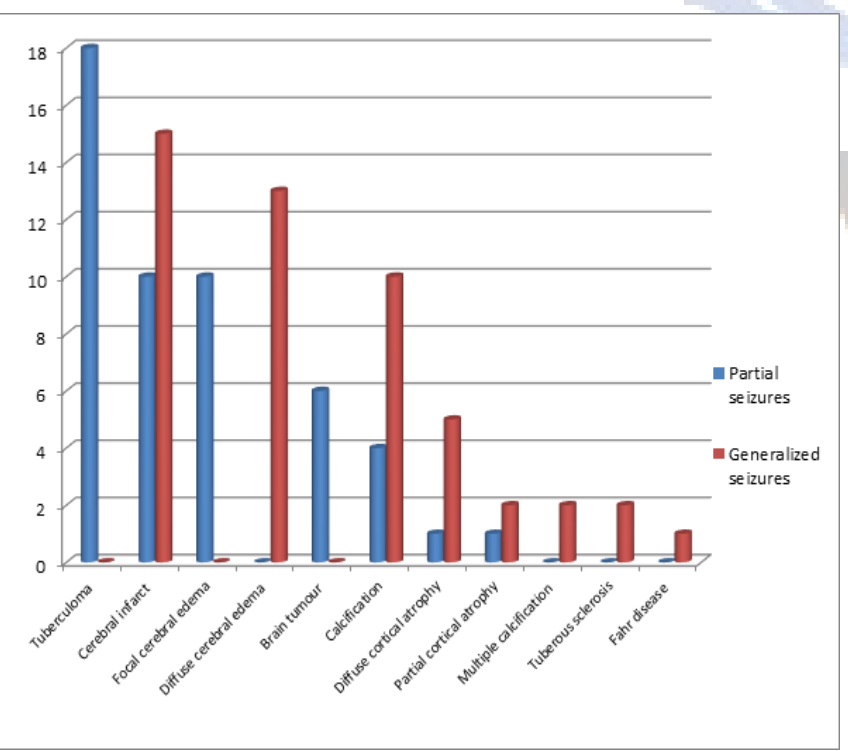

Figure 2: Abnormal CT findings in seizure patients

\begin{tabular}{|c|c|c|c|c|}
\hline $\begin{array}{l}\text { Age } \\
\text { group } \\
\text { (years) }\end{array}$ & $\begin{array}{l}\text { No. of } \\
\text { patients }\end{array}$ & $\begin{array}{l}\text { Partial } \\
\text { seizure }\end{array}$ & $\begin{array}{l}\text { Generalized } \\
\text { seizure }\end{array}$ & $\begin{array}{l}\text { Abnormal } \\
\text { CT } \\
\text { findings }\end{array}$ \\
\hline $\begin{array}{l}\text { Less than } \\
20\end{array}$ & 54 & 25 & 29 & 29 \\
\hline 20 to 40 & 50 & 20 & 30 & 28 \\
\hline 40 to 60 & 48 & 30 & 18 & 21 \\
\hline $\begin{array}{l}\text { More } \\
\text { than } 60\end{array}$ & 46 & 25 & 23 & 22 \\
\hline
\end{tabular}

Table 2: Abnormal CT findings in seizure patients

\begin{tabular}{|l|l|l|}
\hline CT Scan findings & $\begin{array}{l}\text { Partial } \\
\text { seizures }\end{array}$ & Generalized seizures \\
\hline Tuberculoma & 18 & 0 \\
\hline Cerebral infarct & 10 & 15 \\
\hline Focal cerebral edema & 10 & 0 \\
\hline $\begin{array}{l}\text { Diffuse cerebral } \\
\text { edema }\end{array}$ & 0 & 13 \\
\hline Brain tumour & 6 & 0 \\
\hline Calcification & 4 & 10 \\
\hline $\begin{array}{l}\text { Diffuse cortical } \\
\text { atrophy }\end{array}$ & 1 & 5 \\
\hline $\begin{array}{l}\text { Partial cortical } \\
\text { atrophy }\end{array}$ & 1 & 2 \\
\hline Multiple calcification & 0 & 2 \\
\hline Tuberous sclerosis & 0 & 2 \\
\hline Fahr disease & 0 & 1 \\
\hline
\end{tabular}

\section{Discussion}

Computerized tomography (CT) scan uses ionizing radiation and can generate excellent hard tissue imaging contrast with moderately good soft tissue resolution. CT scan has a number of advantages like lower cost, ready accessibility, scan speed, etc. which provide a relatively reliable imaging modality for most patients. In addition, new generation CT scanners can generate an image of the brain in seconds. Although the use of CT for epileptic patients has reduced with availability of MRI, CT is still the imaging of choice for these patients under certain conditions..$^{[7,8]}$ Among 200 patients, 100 patients were with partial seizure while the remaining 100 patients were of generalized seizure. Among these 200 patients, 115 were males while the remaining 85 were females. 54 patients belonged to the age group of less than 20 years, whereas 50 patients belonged to the age group of 20 to 40 years. Remaining 46 patients belonged to the age group of 40 to 60 years. de la Sayette V et al reviewed the CT findings of 387 patients with new-onset seizures after the age of 50 . Seizures were generalized in 212 patients, focal in 160, and indeterminant in 15. CT scanning revealed cerebral atrophy in 113 cases, ischemic lesions in 75, cerebral neoplasms in 20, and no abnormality in 177 cases. Tumours were found in only three patients with generalized seizures, and all three had focal neurological deficits at the time of CT diagnosis, while 17 neoplasms were discovered in patients with a focal seizure disorder. The majority of patients with late-onset epilepsy have a normal CT scan with cerebral atrophy being the most common abnormality detected. Cerebral vascular disease appears to be the most frequently identified cause of late-onset epilepsy, while cerebral neoplasms are uncommon. ${ }^{[9]}$

In the present study, Tuberculoma was found to be present among in 18 patients with partial seizures. Cerebral infarct was found to be present in 10 patients with partial seizures and among 15 patients with generalized seizures. Focal cerebral edema was found to be present in 10 patients with partial seizures. Diffuse cerebral edema was found to be present in 13 patients with generalized seizures. Brain tumour was found to be present among 6 patients with partial seizures. Calcifications were found to be present in 4 
patients with partial seizures and 10 patients with generalized seizures.

Chee MW et al reviewed the CT findings in patients with recurrent seizures. Eighty patients had Computed Tomography (CT) performed for evaluation of epileptic seizures. Abnormal scans were found in 37 of the 80 patients $(46.3 \%)$. Focal CT abnormalities were seen in 26 of the 80 patients $(32.5 \%)$. Tumors were present in four and arteriovenous malformation (AVM) in three. Simple partial motor seizures were most strongly correlated with abnormal scans (five, $45.4 \%$ ). Nineteen out of 21 patients with focal electro-encephalographic (EEG) abnormalities had focal CT abnormality compared to one out of 15 of those with generalised abnormality. $88.9 \%$ of patients with hemiplegia had abnormal scans. Whilst focal EEG abnormalities and abnormal neurologic signs pointed to a higher likelihood of CT abnormality, two subjects who were shown to have vascular malformations had normal EEG and neurologic exams. Routine CT scanning for evaluation of patients with recurrent seizures is advocated. ${ }^{[10]}$ Bajaj $\mathrm{S}$ et al reported the results of computed tomography (CT) in 170 patients who developed seizures. Localized signs could be demonstrated by neurologic examination in $23.5 \%$. CT findings were normal in 64 patients $(37.6 \%)$. The commonest abnormality was a focal ring or disc enhancing lesion in 66 patients $(62.3 \%)$ followed by calcification (18 patients; $16.9 \%)$, cerebral atrophy $(9 ; 8.5 \%)$, vascular lesions $(7 ; 6.6 \%)$, tumours $(4 ; 3.8 \%)$ and congenital hydrocephalus $(2 ; 1.9 \%)$. The occurrence of abnormal CT was higher $(74.3 \%)$ in patients with partial seizures. ${ }^{[11]}$ Patel PJ et al assessed the CT findings in children with seizures only. One hundred and fifteen children with seizures only were studied with Computed Tomography (CT) scan. Eighty percent of the children had normal CT scan; $8.7 \%$ showed cerebral atrophy and in only $11.3 \%$ was there a specific abnormality; such as infarction, porencephalic cysts, and arachnoid cysts. These specific type of abnormalities belong to partial and combined types of seizures and were treated medically. Fifty-seven cases of generalized type of seizures showed only 6 cases of abnormal CT scan and that is only brain atrophy. Based on these findings, they believed that CT scan should not be a part of the routine investigations of children with seizures only, especially those of generalized type. ${ }^{[12]}$

\section{Conclusion}

Under the light of above obtained data, the authors conclude that CT is sensitive for detection of neural lesions and is advocated in seizure patients. However; further studies are recommended.

\section{References}

1. Hankey G, Davies L, Gubbay SS. Long term survival with early childhood intracerebraltumours. J NeurolNeurosurg Psychiatry. 1989;52:778-81.

2. King MA, Newton MR, Jackson GD. Epileptology of the first-seizure presentation: a clinical, electroencephalographic, and magnetic resonance imaging study of 300 consecutive patients. Lancet. 1998;352:1007-1111.

3. Wyllie E, Rothner AD, Luders H. Partial seizures in children: Clinical features, medical treatment, and surgical considerations. PediatrClin North Am. 1989;36:343-64.

4. So EL. Role of neuroimaging in the management of seizure disorders. Mayo Clin Proc. 2002;77:1251-1264.

5. Kho LK, Lawn ND, Dunne JW, Linto J. First seizure presentation: do multiple seizures within 24 hours predict recurrence? Neurology. 2006;67:1047-1049.

6. Commission on Epidemiology and Prognosis, International League Against Epilepsy. Guidelines for epidemiologic studies on epilepsy. Epilepsia 1993;34:592-596.

7. Duncan JS. Imaging and epilepsy. Brain. 1997;120:339-77.

8. Sá de Camargo EC, Koroshetz WJ. Neuroimaging of ischemia and infarction. NeuroRx. 2005;2:265-76.

9. de la Sayette V1, Cosgrove R, Melanson D, Ethier R. CT findings in late-onset epilepsy. Can J Neurol Sci. 1987 Aug;14(3):286-9.

10. Chee MW1, Lim SH, Tjia TL. Computed tomography in patients with recurrent seizures. Ann Acad Med Singapore. 1993 May;22(3 Suppl):431-4.

11. Bajaj S1, Barthwal SP, Dwivedi NC, Maheshwari AK, Goel UC. Contrast computed tomography in epilepsy with special reference to intracranial ring or disc enhancing lesions. J Assoc Physicians India. $1991 \mathrm{Jul} ; 39(7): 543-5$.

12. Patel PJ, Kolawole TM, Mahdi AH, Qteishat WA. Computed tomography (CT) scan findings in children with seizures only. ActaNeurol Scand. 1986 Aug;74(2):165-6.

Copyright: (c) the author(s), publisher. Asian Journal of Medical Radiological Research is an Official Publication of "Society for Health Care \& Research Development". It is an open-access article distributed under the terms of the Creative Commons Attribution Non-Commercial License, which permits unrestricted non-commercial use, distribution, and reproduction in any medium, provided the original work is properly cited.

How to cite this article: Wadhwani ND, Patil NB. Retrospective Evaluation of Radiographic Findings in Patients with Pulmonary Tuberculosis: An Observational Study.Asian J. Med.Radiol.Res. 2019;7(2):04-06.

DOI: dx.doi.org/10.21276/ajmrr.2019.7.2.2 